\title{
New 3D Scan-Method for Quantification of Discretion; Application to Body-Close Incontinence Protection
}

\author{
Anne FARBROT*1, Stefan ROSÉN², Erik NYKVIST ${ }^{2}$, Josefine WIHLBORG ${ }^{1}$ \\ ${ }^{1}$ SCA Hygiene Products AB, Global Hygiene Category, Gothenburg, Sweden; \\ 2 Toponova Engineering AB, Halmstad, Sweden
}

http://dx.doi.org/10.15221/14.218

\begin{abstract}
The present study presents an objective method to quantify discretion in terms of body close fit of incontinence care products. A 3D scan-method based on a structured light sensor and industrial inspection software was developed to record and evaluate different product designs dressed on a mannequin. All of the instrumentation and software are commercially available and performance evaluated in order to assure reproducibility. The methodology is applicable to dry as well as wetted products and has proven useful for comparisons of different pull-on type of disposable incontinence products.
\end{abstract}

Key words: 3D scan, discretion, fit, handheld, metrology, mannequin, incontinence product, design.

\section{Introduction}

Body fit and discretion are of key concern to people living their lives with incontinence, relying on urine-absorbing aids. Obviously, the most important factor for discreteness is leakage security, which depends on many factors related to both product and user and situation. For evaluation of a product, one should always look at the combination of product characteristics e.g. absorption, ease-of-use, fit and discretion in relation to the user/caregiver and the situation. Therefore, discretion and fit are recommended [1] along with leakage security and ease-of-use as important product selection factors. There are no standard measurement methods for substantiation/validation of marketing communication and claims that address product fit nor discreteness.

\subsection{Problem addressed}

Historically, and since incontinence products are judged from the total absorption capacity [2] of the materials, body-worn incontinence protections have been developed -unintentionally- with a bulky appearance. Today's product construction/design and innovative materials make it possible to manufacture well-fitting incontinence products, see for illustration Fig 1. Hence, there is a need for an objective quantification of body-fit in order to compare and substantiate essential product differences.

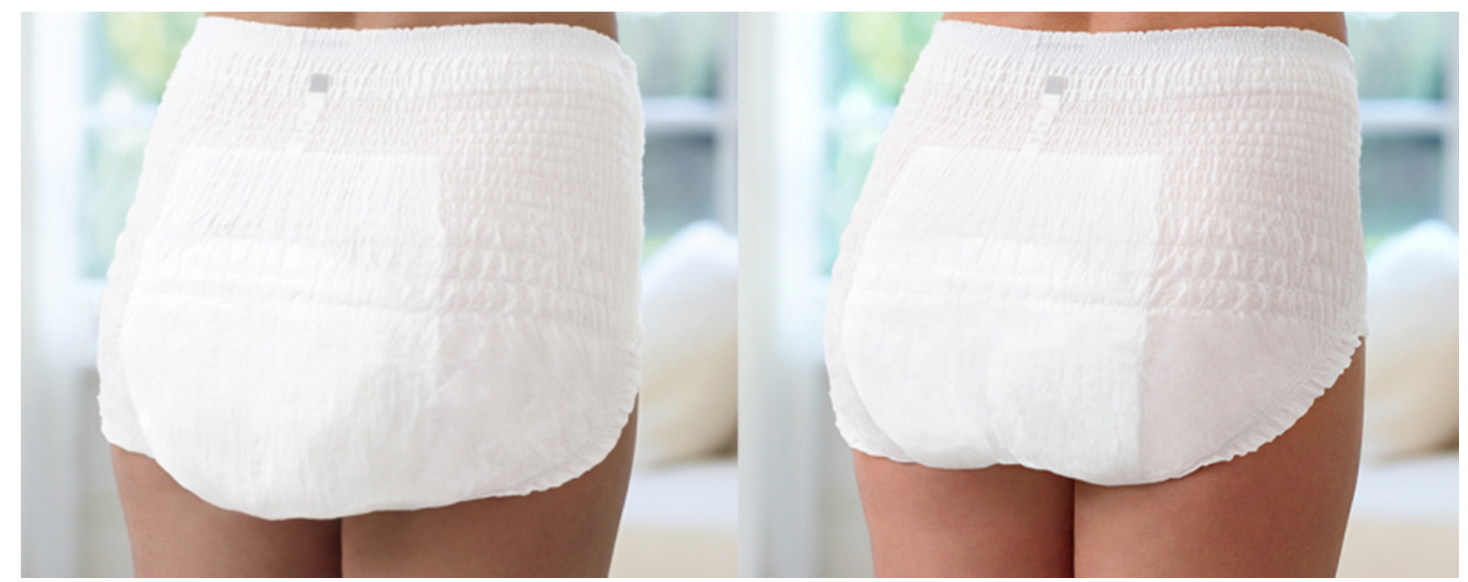

Fig 1. Subjective method for communicating different body-close incontinence protection products.

*Author to whom correspondence should be addressed 
In the past, 3D body-scanning techniques [3] have been constructed as fixed stationary systems. This technology has made it difficult to scan complex geometries, e.g. crotch region of humans and mannequins, where surfaces shadow one another or are hidden by the legs. Mannequins dressed with body-close incontinence protection are examples where this is an important issue. New handheld sensors have been introduced on the market offering flexibility for the scanning operator to scan difficult geometries and judge the scanning result in real time during the scanning.

\subsection{Solution: 3D-scan method}

The present study proposes a new and objective way to measure discreteness. The method is based on a hand held commercially available structured light sensor from Artec Group and industrial inspection software from Geomagic. A mannequin is scanned and used as reference (nominal data) when evaluating and comparing different products. The products are dressed onto the mannequin, scanned and data is saved for inspection using Geomagic Verify. The inspection software uses the nominal data together with the data from the mannequin wearing a product whereby measures such as distances, deviations and volumes can be calculated between the nominal data and the external surface of the product. To ensure accurate measurements and reliable data for decision-making, a metrology framework has been developed to qualify the scanning data.

Thereby, products can be studied and compared in an objective way using standard measurements.

\section{Materials and methods}

\subsection{Instruments}

The data derived from this method is based on accurate measurements done with three components, the Artec Eva (3D scanner, serial\# EV.30.72018541), Artec Studio (software, version 9.2.2.34) and Geomagic Verify (software, build 4.0.0.0). The operator uses the Artec Eva together with Artec Studio to obtain a point cloud. The point cloud is then translated into a mesh and exported to Geomagic Verify as an STL-file. The Artec Eva was chosen because of its accuracy and flexibility as a handheld device. The flexibility is needed to be able to capture the whole product with its creases from every angle.

\subsection{Body-worn incontinence products}

Pull-on-type of incontinence products size $\mathrm{M}$ of five different designs from four different producers were obtained in stores and pharmacies in EU during Oct-Nov 2013. The products were stored in their original packaging and used directly from the package, i.e. they were not pre-conditioned in any way.

\subsection{Mannequin}

A hollow model of the lower abdomen with ladies size 38 (Fig. 2), was used for product fitting.

\subsection{Preparations}

The products were dressed onto the mannequin by the operator using the same procedure with all products to avoid operator introducing differences in fit.

For comparison of dry and wetted products, the dry product is used as nominal reference. First a dry product is scanned. Thereafter, a $300 \mathrm{ml}$ aliquot of simulated urine ( $0.9 \%$ sodium chloride solution) is added to the product through a tube inside the mannequin. Before scanning the wet product it is left to soak for 10 minutes after the liquid is applied.

This way the wet product can be scanned without having the operator interfering with the product. This leads to the ability to accurately and

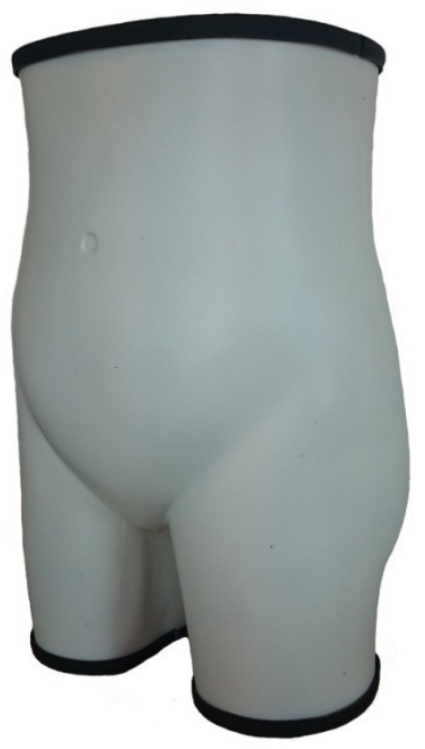

Fig.2. Hollow mannequin. 
objectively study how products change when subjected to liquid.

\subsection{Scan techniques}

The method uses a complete scan of an undressed mannequin as a nominal reference and a complete scan of a mannequin wearing a product as a comparison which gives a multitude of possible ways to measure between the two using only one single scan of the product. In Geomagic Verify the two scans are aligned to each other by using common surfaces that are not affected by the product, i.e. approximately from the bellybutton and above and the legs. By using pre-defined methods of measurement (volume of product, distance from crotch etc.) the data is collected and presented in a unique report for each evaluated product.
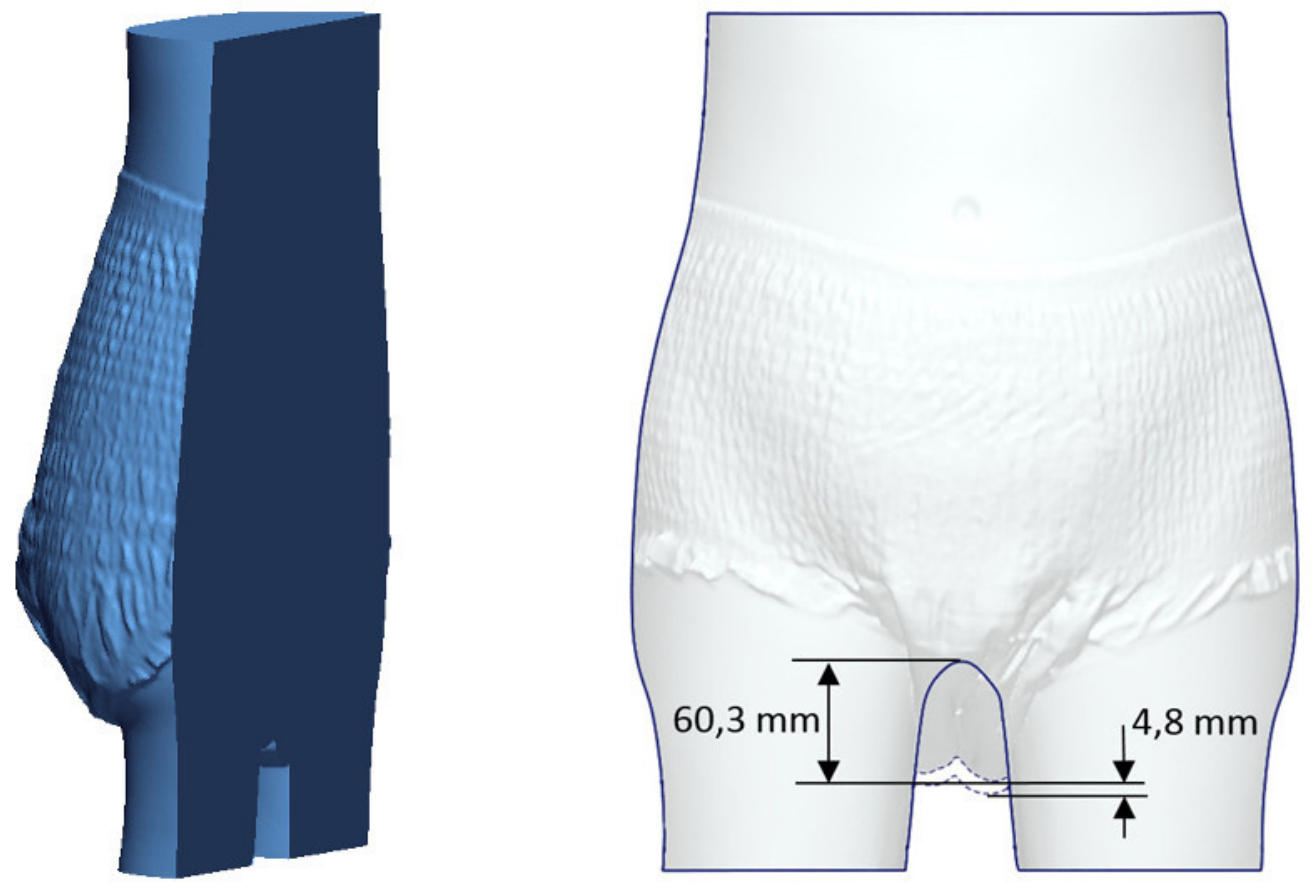

Fig. 3. Measurements of "Body close fit" is represented by the vertical distance, in a defined plane (left), between the highest point in the mannequin's crotch and the lowest point of the product, $60.3 \mathrm{~mm}$ (right). The value 4.8 $\mathrm{mm}$ is the difference between dry and wet product.

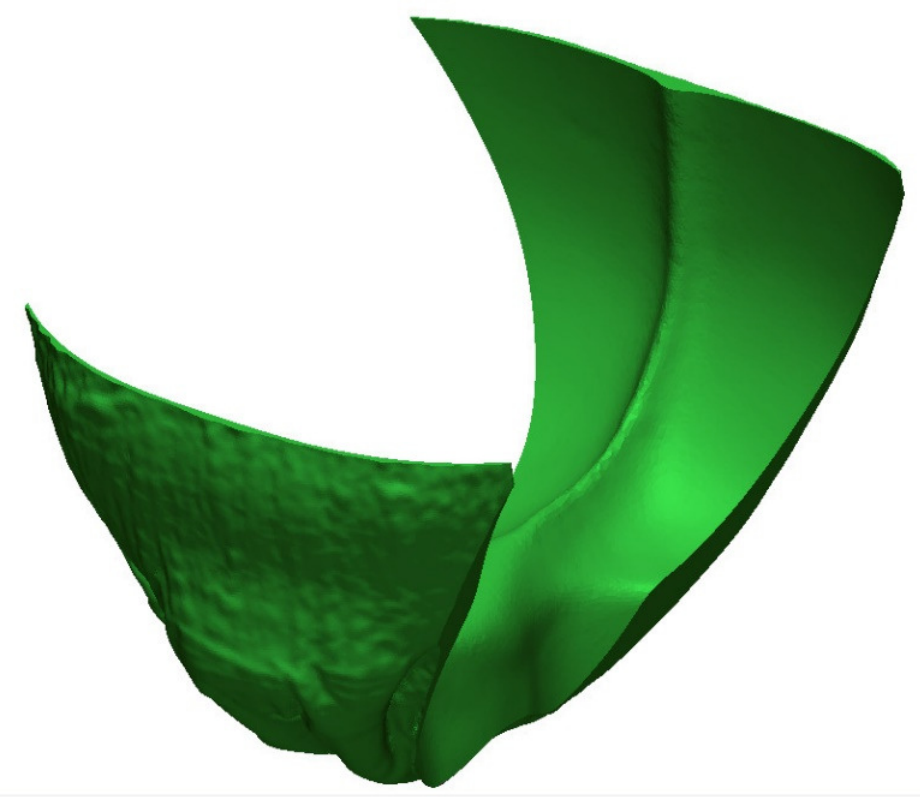

Fig. 4. Graphic representation of "Core Volume". 


\section{Results}

\subsection{Uncertainty/Accuracy}

To evaluate the accuracy of the scanner the mannequin was measured by SP Technical Research Institute of Sweden. The data was then compared in Geomagic Verify with 10 different scans of the same mannequin done with the Artec Eva. Artec Eva unit has a certificate of accuracy in compliance with VDI-Standard: VDI/VDE 2634 Blatt 3 3D-measuring systems - Multiple view systems based on area scanning.

The algorithms in the Geomagic Geometry Calculation Engine were tested for accuracy by three of the world's leading metrology labs, NPL [4], NIST [5] and PTB [6]. All three independent tests found that the geometry fitting algorithms in Geomagic Verify are some of the most accurate available. Note that the tests refer to RapidForm which is the previous name of the software.

The parameters contributing to uncertainty includes Measurement method [7] (repeatability, reference, measurement system accuracy and temperature difference) and Parameter evaluation (repeatability calculation parameters). Conditions include; same measurement procedure, same observer/operator, same instruments, same location, repetition over a short period of time.

Table 1. Measurement method uncertainty.

\begin{tabular}{|c|c|c|}
\hline Characteristics & Standard uncertainty & Uncertainty contributions \\
\hline Repeatability $^{1}$ & $0.12 \mathrm{~mm}$ & 0.12 \\
\hline Reference $^{2}$ & $0.04 \mathrm{~mm}$ & 0.04 \\
\hline $\begin{array}{l}\text { Reported measurement } \\
\text { system accuracy }\end{array}$ & $0.04 \mathrm{~mm}$ & 0.04 \\
\hline Temperature difference $^{4}$ & $2^{\circ} \mathrm{C}$ & 0.031 \\
\hline & Sum of the squares & 0.02 \\
\hline & Summary of uncertainty & 0.14 \\
\hline \multicolumn{2}{|c|}{ Expanded uncertainty, $95 \%$ confidence, $(\mathrm{k}=2)$} & 0.3 \\
\hline
\end{tabular}

Repeatability measuring reference mannequin 10 times (range value).

Reference measurement of mannequin by accredited laboratory. Reported measurement, std dev $0.04 \mathrm{~mm}$. Measurement system accuracy, certificate of compliance, reported accuracy $0.04 \mathrm{~mm}$.

Temperature difference, $20+/-1^{\circ} \mathrm{C}$. Contribution calculated from material expansion of mannequin.

Results show from table 1 that the measurement systems contributes with $+/-0.3 \mathrm{~mm}$ uncertainty. Repeatability is the factor contributing most to the uncertainty.

Table 2. Parameter evaluation uncertainty.

\begin{tabular}{|c|c|c|}
\hline Characteristics & Standard uncertainty & Uncertainty contributions \\
\hline $\begin{array}{l}\text { Summary of measurement } \\
\text { method uncertainty }\end{array}$ & $0.14 \mathrm{~mm}$ & 0.14 \\
\hline Body close $\mathrm{fit}^{6}$ & $0.8 \mathrm{~mm}$ & 0.8 \\
\hline & Sum of the squares & 0.66 \\
\hline & Summary of uncertainty & 0.81 \\
\hline \multicolumn{2}{|c|}{ Expanded uncertainty, $95 \%$ confidence, $(k=2)$} & 1.6 \\
\hline
\end{tabular}

5 Summary of uncertainty, Table 1.

6 Repeatability measuring reference mannequin wearing same product 10 times (range value) using method described in Fig. 3.

From the result for parameter uncertainty, including measurement method, the method has an uncertainty of $+/-1.6 \mathrm{~mm}$ where Body Close fit parameter influence most. The measurement method has low influence on the uncertainty. 


\subsection{Product evaluations}

Table 3. Results of comparison between wet and dry products, five samples of each model. Core Volume as described in Fig. 4. Body close fit as described in Fig. 3.

\begin{tabular}{|c|c|c|c|c|c|c|c|c|c|c|}
\hline Product & \multicolumn{2}{|c|}{$A$} & \multicolumn{2}{|c|}{$B$} & \multicolumn{2}{|c|}{$\mathrm{C}$} & \multicolumn{2}{|c|}{$\mathrm{D}$} & \multicolumn{2}{|c|}{$E$} \\
\hline & $\begin{array}{l}\text { Core } \\
\text { Volume } \\
\text { (I) }\end{array}$ & $\begin{array}{l}\text { Body } \\
\text { close fit } \\
(\mathrm{mm})\end{array}$ & $\begin{array}{l}\text { Core } \\
\text { Volume } \\
\text { (I) }\end{array}$ & $\begin{array}{l}\text { Body } \\
\text { close fit } \\
(\mathrm{mm})\end{array}$ & $\begin{array}{l}\text { Core } \\
\text { Volume } \\
\text { (I) }\end{array}$ & $\begin{array}{l}\text { Body } \\
\text { close fit } \\
(\mathrm{mm})\end{array}$ & $\begin{array}{l}\text { Core } \\
\text { Volume } \\
\text { (I) }\end{array}$ & $\begin{array}{l}\text { Body } \\
\text { close fit } \\
(\mathrm{mm})\end{array}$ & $\begin{array}{l}\text { Core } \\
\text { Volume } \\
\text { (I) }\end{array}$ & $\begin{array}{l}\text { Body } \\
\text { close fit } \\
(\mathrm{mm})\end{array}$ \\
\hline 1-Wet & 1,478 & 74,4 & 1,196 & 67,4 & 1,174 & 80,8 & 1,477 & 78,7 & 1,559 & 88,5 \\
\hline 1-Dry & 1,313 & 66,3 & 1,044 & 60,6 & 1,029 & 76,5 & 1,377 & 73,2 & 1,531 & 88,3 \\
\hline 1-Difference & 0,17 & 8,10 & 0,15 & 6,8 & 0,15 & 4,30 & 0,10 & 5,50 & 0,03 & 0,20 \\
\hline 2-Wet & 1,48 & 76,8 & 1,192 & 62,5 & 1,262 & 80,3 & 1,459 & 79 & 1,641 & 86,3 \\
\hline 2-Dry & 1,372 & 71 & 1,075 & 59,1 & 1,142 & 75,3 & 1,312 & 69,4 & 1,602 & 84,2 \\
\hline 2-Difference & 0,11 & 5,80 & 0,12 & 3,40 & 0,12 & 5,00 & 0,15 & 9,60 & 0,04 & 2,10 \\
\hline 3-Wet & 1,519 & 85,8 & 1,228 & 65,7 & 1,304 & 80,7 & 1,444 & 75,6 & 1,587 & 80 \\
\hline 3-Dry & 1,379 & 77,4 & 1,099 & 59,6 & 1,218 & 76,2 & 1,316 & 67,4 & 1,563 & 78,2 \\
\hline 3-Difference & 0,14 & 8,40 & 0,13 & 6,10 & 0,09 & 4,50 & 0,13 & 8,20 & 0,02 & 1,80 \\
\hline 4-Wet & 1,483 & 82,8 & 1,202 & 65,4 & 1,339 & 82,4 & 1,454 & 80,4 & 1,651 & 82,6 \\
\hline 4-Dry & 1,356 & 75,5 & 1,159 & 62,8 & 1,221 & 76,9 & 1,368 & 72,9 & 1,632 & 78,5 \\
\hline 4-Difference & 0,13 & 7,30 & 0,04 & 2,60 & 0,12 & 5,50 & 0,09 & 7,50 & 0,02 & 4,10 \\
\hline 5-Wet & 1,445 & 76,9 & 1,193 & 64,6 & 1,305 & 83,9 & 1,469 & 72,5 & 1,561 & 80,6 \\
\hline 5-Dry & 1,318 & 69,9 & 1,043 & 59,3 & 1,223 & 77,1 & 1,341 & 67,3 & 1,49 & 73,3 \\
\hline 5-Difference & 0,13 & 7,00 & 0,15 & 5,30 & 0,08 & 6,80 & 0,13 & 5,20 & 0,07 & 7,30 \\
\hline Mean value wet & 1,48 & 79,3 & 1,20 & 65,1 & 1,28 & 81,6 & 1,46 & 77,2 & 1,60 & 83,6 \\
\hline Mean value dry & 1,35 & 72,0 & 1,08 & 60,3 & 1,17 & 76,4 & 1,34 & 70,0 & 1,56 & 80,5 \\
\hline Mean value diff. & 0,13 & 7,3 & 0,12 & 4,8 & 0,11 & 5,2 & 0,12 & 7,2 & 0,04 & 3,1 \\
\hline
\end{tabular}

The data in table 3 shows that product B displays the smallest mean value for "Body close fit" (dry) among the tested products. Product E displays the largest bulkiness in terms of "Body close fit", but the smallest difference between dry and wet product, $3.1 \mathrm{~mm}$. A noticeable observation is that the measured volume expansion of "Core volume" (dry/wet) is almost consistent among products A, B, C and $D(0.11-0.13 \mathrm{I})$, while product $E$ shows a smaller difference between wet and dry.

\section{Discussion and conclusions}

Incontinence in itself is perceived as undignifying, which is why discretion is so important. Discretion depends on many aspects of coping with the physiological disability, ranging from handling of boxes and products to wearing and disposing of the protection. There are many publications addressing the problem from a Quality-of-Life (QoL)-perspective [8, 9], underlining the effect of incontinence on a person's psychological health. Still, no study has presented a method like the present; a method that turns user needs regarding discretion into tangible numbers. The development of this 3D scan method will enable the benchmarking of product designs and thus support users in product selection. We used the method to quantify product bulkiness, where the critical areas had been identified in user tests [10]. In table 3 it is seen that the five products could be ranked as measured by bulkiness with the new 3D-scan method. Hence, fact-based evaluation of discretion can be provided.

The method is ground breaking in that it enables visualization and quantification of functional differences (body-close fit and discretion) in designs. These differences have an impact on the user experience of the product, thus influencing QoL. Therefore it is important that this kind of method utilizing state-of-the art 3D-technology is developed, standardized and applied. For further improvements in terms of robustness of the method, an MSA (Measurement System Analysis) will be conducted to define the measurement uncertainty and factors most influencing the results. 


\section{References}

[1] ISO 15621 (2011): Urine absorbing aids - General guidelines on evaluation

[2] ISO 11948-1 (1996): Urine absorbing aids - Part I: Whole-product testing

[3] N D'Apuzzo 3D body scanning technologies with applications to the fashion and apparel industry, - Electronic Imaging 2007, 2007 - proceedings.spiedigitallibrary.org

[4] Test results, https://rapidform.s3.amazonaws.com/metrologytests/Rapidform NPL Evaluation.pdf, accessed 2014-09-03.

[5] Test results, https://rapidform.s3.amazonaws.com/metrologytests/Rapidform NIST Special Test.pdf, accessed 2014-09-03.

[6] Test results, https://rapidform.s3.amazonaws.com/metrology-tests/Rapidform PTB Results.pdf, accessed 2014-09-03.

[7] National standard "Mätosäkerhet för verkstadsindustrin - GPS" SIS HB 546, 1st edition, ISBN:978-91-7162-718-6

[8] E. Dugan, S.J. Cohen, D.R. Bland, J.S. Preisser, C.C. Davis, P.K. Suggs et al., "The assosiation of depressive symptoms and urinary incontinence among older adults", Journal of the American Geriatrics Society, 2000: 48(4) pp 413-416.

[9] S. Heidrich, T. Wells. "Effects of Urinary Incontinence: Psycological Well-being and Distress in Older Community-Dwelling Women", Journal of Gerontological Nursing, 2004: 30(5)

[10] SCA Hygiene Products AB, Unpublished consumer research. 